\title{
Factors Affecting Morbidity, Mortality, and Recurrence in Incarcerated Femoral Hernia
}

\author{
Tolga Kalayci ${ }^{1}$, Umit Haluk Iliklerden ${ }^{2}$ and Mehmet Cetin Kotan ${ }^{2}$ \\ ${ }^{1}$ Department of General Surgery, Erzurum Regional Education and Research Hospital, Erzurum, Turkey \\ ${ }^{2}$ Department of General Surgery, Faculty of Medicine, Van Yuzuncu Yil University, Van, Turkey
}

\begin{abstract}
Objective: To ascertain the factors that govern morbidity, mortality, and recurrence in incarcerated femoral hernia.

Study Design: Observational study.

Place and Duration of Study: Department of General Surgery, Faculty of Medicine, Van Yuzuncu Yil University, Van, Turkey, between January 2010 and January 2020.

Methodology: This observational study included patients operated on due to incarcerated femoral hernias under emergency conditions. The preoperative, intraoperative, and postoperative parameters of the patients were gathered. The study excluded pregnant patients and patients in the pediatric age group (0-18 years). Mann-Whitney U-test was used to compare quantitative variables. In addition, a Chi-square test and Likelihood-ratio test were used to compare the qualitative variables. A p-value $<0.05$ was deemed statistically significant.

Results: The mean age of the 50 patients was $54.56 \pm 19.34$ (19-91) years and the female/male ratio was 33:17. The morbidity, mortality, and recurrence rates of the study were $14 \%, 4 \%$, and $6 \%$ respectively. Higher morbidity was observed in patients who had preoperative nausea $(p=0.003)$, vomiting $(p<0.001)$, tachycardia $(p<0.001)$, recurrent hernia ( $p$ $<0.001)$, surgery under general anesthesia $(p<0.001)$ or who underwent both laparotomy $(p=0.007)$ and visceral resection during surgery $(p<0.001)$. Higher rates of mortality were observed in patients who had preoperative tachycardia $(p=0.054)$ or visceral resection during surgery $(p=0.029)$. However, the study identified no factors affecting recurrence.

Conclusion: In cases of incarcerated femoral hernia, symptoms of intestinal obstruction or signs of strangulation are more important in the development of postoperative morbidity. In addition, the probability of mortality is higher in patients who had preoperative tachycardia and in patients who underwent visceral resection. To the extent possible, regional anesthesia should be preferred in suitable cases.
\end{abstract}

Key Words: Femoral hernia, Laparotomy, Morbidity, Mortality, Recurrence.

How to cite this article: Kalayci T, Iliklerden UH, Kotan MC. Factors Affecting Morbidity, Mortality, and Recurrence in Incarcerated Femoral Hernia. J Coll Physicians Surg Pak 2022; 32(02):213-219.

\section{INTRODUCTION}

The femoral ring is an anatomical structure bounded laterally by the femoral vein, anteriorly by the inguinal ligament, medially by the lacunar ligament and posteriorly by the pectineal ligament. A femoral hernia is the protrusion of preperitoneal fat or abdominopelvic organs from the femoral ring into the femoral canal under the inguinal ligament. ${ }^{1}$ Femoral hernia is an uncommon condition, rare among groin hernias. ${ }^{2}$ The prevalence of femoral hernia is variable, but it is seen in less than $5 \%$ of cases on average. ${ }^{3}$

Correspondence to: Tolga Kalayci, Department of General Surgery, Erzurum Regional Education and Research Hospital, Erzurum, Turkey

E-mail:dr.tolgakalayci@gmail.com

Received: August 13, 2021; Revised: September 26, 2021;

Accepted: December 06, 2021

DOI: https://doi.org/10.29271/jcpsp.2022.02.213
Despite rarity offemoral hernia, itis known that its risk of incarceration is relatively higher due to the anatomical structure of the femoral canal. Femoral hernias are also difficult to diagnose due to the depth of their localisation. ${ }^{4}$ Therefore, femoral hernia cases appear as emergency cases, ${ }^{5}$ and the probability of visceral resection is higher.

The diagnosis and treatment of femoral hernias remains challenging problems for surgeons. Due to the tendency of the hernia to move up the inguinal ligament, it can sometimes be confused with an inguinal hernia, with the correct diagnosis being made during surgery. ${ }^{6}$ The only correct treatment option is surgery. Because of the high incidence of strangulation, it is important to treat a femoral hernia as soon as the condition is noticed. ${ }^{7}$ In the case of incarceration/strangulation, emergency surgery is required, regardless of the patient's condition or age. However, in these cases, morbidity and mortality are significantly increased. ${ }^{8}$

Various operative techniques have been defined to treat femoral hernias. The main purpose of surgery is to reduce the hernia's area, remove the hernia sac and close the hernia opening. Hernia 
repair is possible using prosthetic materials in addition to basic hernia repair surgery, which can be performed as open surgery or via laparoscopy. ${ }^{9}$

The aim of this study was to identify the factors affecting morbidity, mortality, and recurrence in cases of incarcerated femoral hernias using a review of the literature and a large series of patients.

\section{METHODOLOGY}

The study included patients who had been admitted to Medical Faculty of Van Yuzuncu Yil University between 2010 and 2020 with complaints of inguinal pain and who were operated on in the general surgery department and diagnosed as having incarcerated femoral hernia. The study excluded pregnant patients and those in the pediatric age group (0-18 years). After receiving approval from the Non-invasive Clinical Research Ethics, the cases operated on due to incarcerated femoral hernias were examined, and 50 were found suitable for inclusion in the study.

The hospital's computer system and archived images of patients' medical records were used to identify their preoperative parameters, including patients' characteristics (age, gender), signs and symptoms at admission, diagnostic tools used, hernia location and history of previous hernia surgery. The intraoperative parametersidentified were thetypes of anesthesia and surgery used, the need forlaparotomy ororgan resection and the use of prosthetic materials during hernia repair. The postoperative parameters identified included complications, length of hospital stay, mortality and recurrence. Patients who developed complications in the 30 days after surgery were considered as the morbidity-positive group, and those without complications were considered as the morbidity-negative group. On the other hand, patients who died in the 30 days after surgery were considered as the mortality-positive group, and those who survive were considered as the mortality-negative group. The differences between the groups according to morbidity and mortality were compared.

To confirm the presence of recurrence, patients were telephoned. Moreover, their hospital admissions were confirmed using the data system of the Ministry of Health, Republic of Turkey. Recurrence was not considered in patients who had no groin complaints. Such complaints were present in five patients, and they were called to the hospital for detailed examinations, but no recurrences were identified. However, three (6\%) patients were operated due to recurrent femoral hernia. Patients with recurrence after surgery were considered as the recurrence-positive group, and those without recurrence were considered as the recurrence-negative group.

The aim of this study was to identify the morbidity, mortality and recurrence factors related to incarcerated femoral hernias. Statistical evaluations were conducted using SPSS version 22.0 (IBM, Armonk, NY, USA). The normality distribution of the quantitative variables was checked using Shapiro-Wilk test. According to the results of this test, Mann-Whitney U-test was used. In addi- tion, a Chi-square test and Likelihood-ratio test were used to compare the qualitative variables. A p-value $<0.05$ was considered statistically significant.

\section{RESULTS}

The mean age of the 50 patients was $54.56 \pm 19.34$ years (range: 19-91), and the female/male ratio was 33:17. The most common symptom was inguinal pain, present in $100 \%$ of the cases. Other signs and symptoms occurred as follows: abdominal pain in 42 (84\%) patients, nausea in 16 (32\%), tachycardia in $12(24 \%)$ and vomiting in $8(16 \%)$ patients. Routine physical examination was performed on all patients in order to reduce the hernia contents preoperatively. Because the hernia content was not reduced, inguinal ultrasonography (USG) was performed on all patients as first step imaging tool.

Computed tomography (CT) was performed after USG, to evaluate both intra-abdominal pathology and proximal/distal intestinal loop in 15 (30\%) patients with blood supply problems (reduction/absence) of the intestinal loop in the hernia sac. In the inguinal region evaluation on CT scan, fluid in the hernia sac and oedema in the intestinal wall were detected in all patients, while dilatation in the proximal intestinal loops (10 patients) and ileus (5 patients) were observed in the intra-abdominal evaluation. Of the 50 patients, 27 (54\%) were right-sided and 23 left-sided. There were no bilateral cases, and five patients (10\%) had histories of hernia surgery. Table I shows the clinical features of the patients.

Regional anesthesia was preferred in the 32 cases in which the omentum was in the hernia sac. However, in four of these cases, the patient did not tolerate regional anesthesia during surgery, so general anesthesia was added. In addition, general anesthesia was the first choice for patients in whom the small intestine or colon were in the hernia sac. All patients were operated on using the open surgery technique and a routine inguinal oblique incision. In addition to this oblique incision, in four cases, a midline lower umbilical incision was added. In three of these four cases, a midline incision was also added to facilitate an intestinal resection. In the fourth case, a midline incision was added to repair a corona mortis injury.

Of the 50 patients, 32 (64\%) had incarcerated omental tissue in the hernia sac, 17 had small intestine in the sac, and 1 had sigmoid colon. In one case, omental resection was performed due to omental necrosis. Of the 17 (34\%) patients, who had an incarcerated small intestine segment in the hernia sac, 10 avoided intestinal resection due to normalisation of colour and circulation during a perioperative wait of about 20 minutes and the use of hot compression and checks. However, in five patients, segmental intestinal resection withend-to-endanastomosis was performed due to strangulation. In the remaining two patients, due to a small amount of intestinal perforation, double-layer intestinal perforation repair was performed. In one (2\%) patient, who had a strangulated sigmoid colon segment in the hernia sac, due to a 5-mm colonic perforation, double-layer repair was performed without laparotomy. 
Table I: The clinical features of the patients operated due to incarcerated femoralhernia.

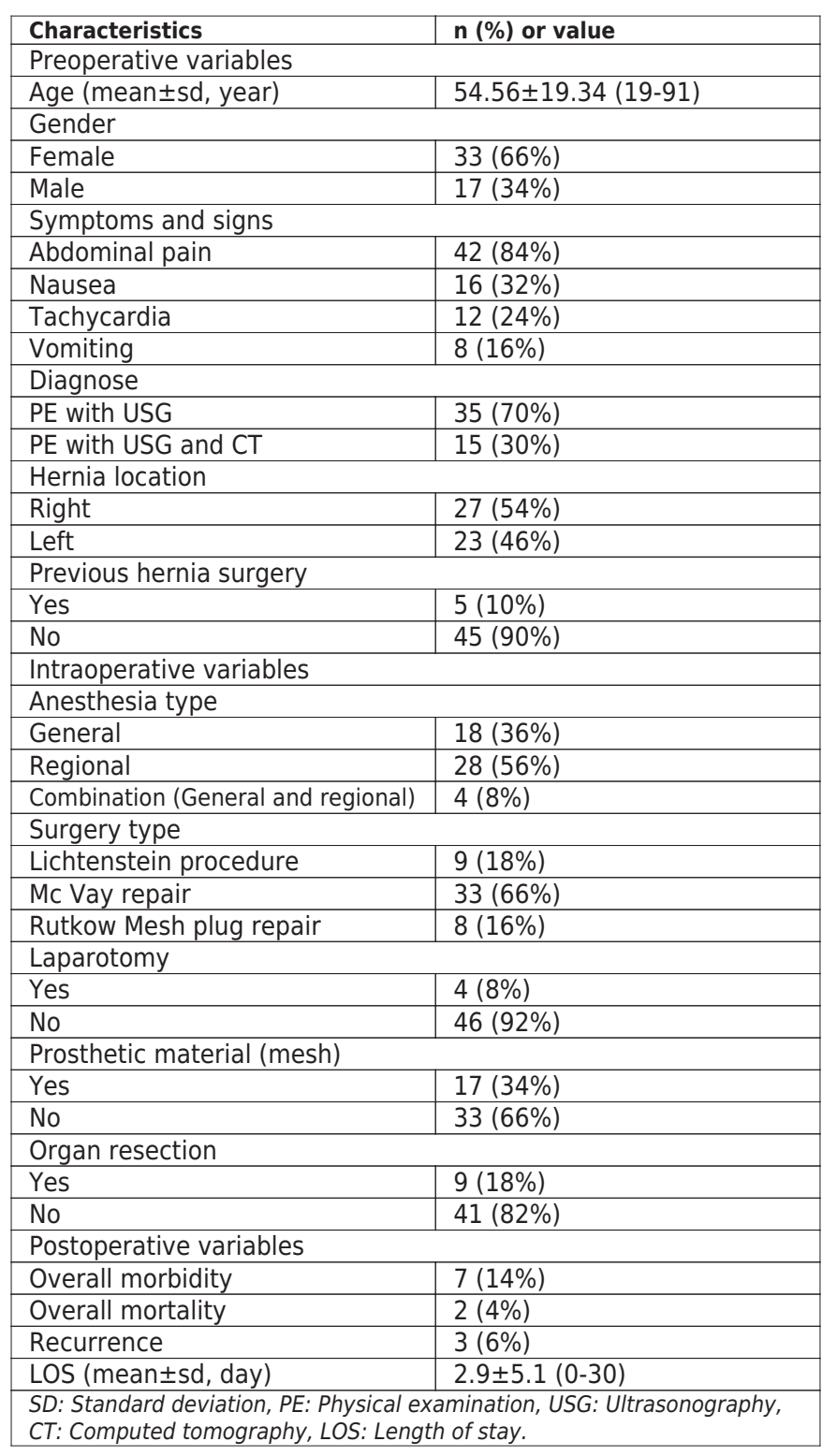

The McVay herniorrhaphy was used on 33 (66\%) patients, the Lichtenstein procedure was used on 9 (18\%) and the Rutkow plug technique was used on 8 (16\%). In four patients, a midline laparotomy was used as well as one of the other three surgery types.

The retrospective's rates of morbidity and mortality were $14 \%$ and $4 \%$, respectively. Seroma was seen in three patients, haematoma in one, ileus in one and pneumonia in two (one a case of hospital-acquired pneumonia and the other aspiration pneumonia).

The mean hospital stay was 2.9 (0-30) days. The patient who had aspiration pneumonia died on the $21^{\text {st }}$ day of intensive care unit follow-up. Another patient died in the early postoperative period due to comorbid diseases (uncontrolled hypertension and severe chronic obstructive lung disease). Recurrences were seen in only three $(6 \%)$ patients, and were detected at the $12^{\text {th }}, 15^{\text {th }}$ and $80^{\text {th }}$ months after the first surgery. The mean follow-up period was 72.2 \pm 30.4 (0-130) months.
Table II: Comparison of patients' variables by morbidity.

\begin{tabular}{|c|c|c|c|}
\hline Variables & $\begin{array}{l}\text { Morbidity (+) } \\
(\mathrm{n}=7)\end{array}$ & $\begin{array}{l}\text { Morbidity (-) } \\
(n=43)\end{array}$ & p-value \\
\hline $\begin{array}{l}\text { Age (median, } \\
\text { IQR) }\end{array}$ & $70(\mathrm{IQR}=46)$ & $51(\mathrm{IQR}=36)$ & $0.321 *$ \\
\hline \multicolumn{3}{|l|}{ Gender } & $0.677^{* *}$ \\
\hline Female & $4(12.1 \%)$ & $29(87.9 \%)$ & \\
\hline Male & $3(17.6 \%)$ & $14(82.4 \%)$ & \\
\hline \multicolumn{3}{|l|}{ Abdominal pain } & $0.580 * *$ \\
\hline Yes & $7(16.7 \%)$ & $35(83.3 \%)$ & \\
\hline No & $0(0 \%)$ & $8(100 \%)$ & \\
\hline \multicolumn{3}{|l|}{ Nausea } & $0.003 * *$ \\
\hline Yes & $6(37.5 \%)$ & $10(62.5 \%)$ & \\
\hline No & $1(2.9 \%)$ & $33(97.1 \%)$ & \\
\hline \multicolumn{3}{|l|}{ Tachycardia } & $<0.001^{* *}$ \\
\hline Yes & $7(58.3 \%)$ & $5(41.7 \%)$ & \\
\hline No & $0(0 \%)$ & $38(100 \%)$ & \\
\hline \multicolumn{3}{|l|}{ Vomiting } & $<0.001 * *$ \\
\hline Yes & $5(62.5 \%)$ & $3(37.5 \%)$ & \\
\hline No & $2(4.8 \%)$ & $40(95.2 \%)$ & \\
\hline \multicolumn{3}{|l|}{ Diagnose } & $0.02^{* *}$ \\
\hline PE with USG & $2(5.7 \%)$ & $33(94.3 \%)$ & \\
\hline $\begin{array}{l}\text { PE with USG } \\
\text { and CT }\end{array}$ & $5(33.3 \%)$ & $10(66.7 \%)$ & \\
\hline \multicolumn{3}{|l|}{ Hernia location } & $0.430 * *$ \\
\hline Right & $5(18.5 \%)$ & $22(81.5 \%)$ & \\
\hline Left & $2(8.7 \%)$ & $21(91.3 \%)$ & \\
\hline \multicolumn{3}{|c|}{ Previous hernia surgery } & $0.001 * *$ \\
\hline Yes & $4(80 \%)$ & $1(20 \%)$ & \\
\hline No & $3(6.7 \%)$ & $42(93.3 \%)$ & \\
\hline \multicolumn{3}{|l|}{ Anesthesia type } & $<0.001^{* * *}$ \\
\hline General & $7(38.9 \%)$ & $11(61.1 \%)$ & \\
\hline Regional & $0(0 \%)$ & $28(100 \%)$ & \\
\hline Combination & $0(0 \%)$ & $4(100 \%)$ & \\
\hline \multicolumn{3}{|l|}{ Surgery type } & $0.171 * * *$ \\
\hline $\begin{array}{l}\text { Lichtenstein } \\
\text { procedure }\end{array}$ & $1(11.1 \%)$ & $8(88.9 \%)$ & \\
\hline Mc Vay repair & $3(9.1 \%)$ & $30(90.9 \%)$ & \\
\hline $\begin{array}{l}\text { Rutkow mesh } \\
\text { plug repair }\end{array}$ & $3(37.5 \%)$ & $5(62.5 \%)$ & \\
\hline \multicolumn{3}{|l|}{ Laparotomy } & $0.007^{* *}$ \\
\hline Yes & $3(75 \%)$ & $1(25 \%)$ & \\
\hline No & $4(8.7 \%)$ & $42(91.3 \%)$ & \\
\hline \multicolumn{3}{|c|}{ Prosthetic material (Mesh) } & $0.677 * *$ \\
\hline Yes & $3(17.6 \%)$ & $14(82.4 \%)$ & \\
\hline No & $4(12.1 \%)$ & $29(87.9 \%)$ & \\
\hline \multicolumn{3}{|l|}{ Organ resection } & $0.001 * *$ \\
\hline Yes & $5(55.6 \%)$ & $4(44.4 \%)$ & \\
\hline No & $2(4.9 \%)$ & $39(95.1 \%)$ & \\
\hline $\begin{array}{l}\text { LOS (median, } \\
\text { IOR) }\end{array}$ & $6(\mathrm{IQR}=19)$ & $1(\mathrm{IQR}=1)$ & $<0.001 *$ \\
\hline
\end{tabular}

Higher morbidity was observed in patients who had preoperative nausea ( $p=0.003)$, vomiting $(p<0.001)$, tachycardia ( $p$ $<0.001)$, CT used for diagnosis $(p=0.02)$, a previous recurrent hernia ( $p=0.001)$, surgery under general anesthesia ( $p$ $<0.001)$ and both laparotomy $(p=0.007)$ and organ resection during surgery ( $p<0.001$, Table II). Higher mortality was observed in patients who had preoperative tachycardia ( $p=$ 0.054 ) or organ resection during surgery ( $p=0.029$, Table III). However, the study identified no factors affecting recurrence (TableIV).

Table III: Comparison of patients' variables by mortality. 


\begin{tabular}{|c|c|c|c|}
\hline Variables & $\begin{array}{l}\text { Mortality (+) } \\
(n=2)\end{array}$ & $\begin{array}{l}\text { Mortality (-) } \\
(n=48)\end{array}$ & $\mathrm{p}$-value \\
\hline Age (Median, IQR) & 64 (IQR=None) & $51(\mathrm{IQR}=36)$ & $0.552^{*}$ \\
\hline \multicolumn{3}{|l|}{ Gender } & $0.542^{* *}$ \\
\hline Female & $2(6.1 \%)$ & 31 (93.9\%) & \\
\hline Male & $0(0 \%)$ & $17(100 \%)$ & \\
\hline \multicolumn{3}{|l|}{ Abdominal pain } & $1.000^{* *}$ \\
\hline Yes & $2(4.8 \%)$ & $40(95.2 \%)$ & \\
\hline No & $0(0 \%)$ & $8(100 \%)$ & \\
\hline \multicolumn{3}{|l|}{ Nausea } & $0.542^{* *}$ \\
\hline Yes & $1(6.3 \%)$ & $15(93.8 \%)$ & \\
\hline No & $1(2.9 \%)$ & $33(97.1 \%)$ & \\
\hline \multicolumn{3}{|l|}{ Tachycardia } & $0.054^{* *}$ \\
\hline Yes & $2(16.7 \%)$ & $10(83.3 \%)$ & \\
\hline No & $0(0 \%)$ & $38(100 \%)$ & \\
\hline \multicolumn{3}{|l|}{ Vomiting } & $0.297^{* *}$ \\
\hline Yes & $1(12.5 \%)$ & $7(87.5 \%)$ & \\
\hline No & $1(2.4 \%)$ & $41(97.6 \%)$ & \\
\hline \multicolumn{3}{|l|}{ Diagnose } & $0.086^{* *}$ \\
\hline PE with USG & $0(0 \%)$ & $35(100 \%)$ & \\
\hline $\begin{array}{l}\text { PE with USG and } \\
\text { CT }\end{array}$ & $2(13.3 \%)$ & $13(86.7 \%)$ & \\
\hline \multicolumn{3}{|l|}{ Hernia location } & $0.493^{* *}$ \\
\hline Right & $2(7.4 \%)$ & $25(92.6 \%)$ & \\
\hline Left & $0(0 \%)$ & $23(100 \%)$ & \\
\hline \multicolumn{3}{|c|}{ Previous hernia surgery } & $0.192^{* *}$ \\
\hline Yes & $1(20 \%)$ & $4(80 \%)$ & \\
\hline No & $1(2.2 \%)$ & $44(97.8 \%)$ & \\
\hline \multicolumn{3}{|l|}{ Anesthesia type } & $0.120 * * *$ \\
\hline General & $2(11.1 \%)$ & $16(88.9 \%)$ & \\
\hline Regional & $0(0 \%)$ & $28(100 \%)$ & \\
\hline Combination & $0(0 \%)$ & $4(100 \%)$ & \\
\hline \multicolumn{3}{|l|}{ Surgery Type } & $0.426 * * *$ \\
\hline $\begin{array}{l}\text { Lichtenstein } \\
\text { procedure }\end{array}$ & $0(0 \%)$ & $9(100 \%)$ & \\
\hline Mc Vay repair & $2(6.1 \%)$ & 31 (93.9\%) & \\
\hline $\begin{array}{l}\text { Rutkow mesh plug } \\
\text { repair }\end{array}$ & $0(0 \%)$ & $8(100 \%)$ & \\
\hline \multicolumn{3}{|l|}{ Laparotomy } & $0.155^{* *}$ \\
\hline Yes & $1(25 \%)$ & $3(75 \%)$ & \\
\hline No & $1(2.2 \%)$ & $45(97.8 \%)$ & \\
\hline \multicolumn{3}{|c|}{ Prosthetic material (Mesh) } & $0.542^{* *}$ \\
\hline Yes & $0(0 \%)$ & $17(100 \%)$ & \\
\hline No & $2(6.1 \%)$ & 31 (93.9\%) & \\
\hline \multicolumn{3}{|l|}{ Organ resection } & $0.029 * *$ \\
\hline Yes & $2(22.9 \%)$ & $7(77.8 \%)$ & \\
\hline No & $0(0 \%)$ & $41(100 \%)$ & \\
\hline \multicolumn{3}{|l|}{ Overall morbidity } & $0.263^{* *}$ \\
\hline Yes & $1(14.3 \%)$ & $6(85.7 \%)$ & \\
\hline No & $1(2.3 \%)$ & $42(97.7 \%)$ & \\
\hline LOS (Median, IQR) & 10.50 (IQR=None) & $1(\mathrm{IQR}=1)$ & $0.955^{*}$ \\
\hline
\end{tabular}

\begin{tabular}{|c|c|c|c|}
\hline No & $2(4.8 \%)$ & $40(95.2 \%)$ & \\
\hline \multicolumn{3}{|l|}{ Diagnose } & $1.000^{* *}$ \\
\hline PE with USG & $2(5.7 \%)$ & $33(94.3 \%)$ & \\
\hline $\begin{array}{l}\text { PE with USG } \\
\text { and CT }\end{array}$ & $1(6.7 \%)$ & $14(93.3 \%)$ & \\
\hline \multicolumn{3}{|c|}{ Previous hernia surgery } & $1.000^{* *}$ \\
\hline Yes & $0(0 \%)$ & $5(100 \%)$ & \\
\hline No & $3(6.7 \%)$ & $42(93.3 \%)$ & \\
\hline \multicolumn{3}{|l|}{ Hernia location } & $0.090^{* *}$ \\
\hline Right & $0(0 \%)$ & $27(100 \%)$ & \\
\hline Left & $3(13 \%)$ & $20(87 \%)$ & \\
\hline \multicolumn{3}{|l|}{ Anesthesia type } & $0.755^{* * *}$ \\
\hline General & $1(5.6 \%)$ & $17(94.4 \%)$ & \\
\hline Regional & $2(7.1 \%)$ & $26(92.9 \%)$ & \\
\hline Combination & $0(0 \%)$ & $4(100 \%)$ & \\
\hline \multicolumn{3}{|l|}{ Surgery type } & $0.274^{* * *}$ \\
\hline $\begin{array}{l}\text { Lichtenstein } \\
\text { procedure }\end{array}$ & $0(0 \%)$ & $9(100 \%)$ & \\
\hline Mc Vay repair & $3(9.1 \%)$ & $30(90.9 \%)$ & \\
\hline $\begin{array}{l}\text { Rutkow mesh } \\
\text { plug repair }\end{array}$ & $0(0 \%)$ & $8(100 \%)$ & \\
\hline \multicolumn{3}{|l|}{ Laparotomy } & $1.000^{* *}$ \\
\hline Yes & $0(0 \%)$ & $4(100 \%)$ & \\
\hline No & $3(6.5 \%)$ & $43(93.5 \%)$ & \\
\hline \multicolumn{3}{|c|}{ Prosthetic material (Mesh) } & 0.542 \\
\hline Yes & $0(0 \%)$ & $17(100 \%)$ & \\
\hline No & $3(9.1 \%)$ & $30(90.9 \%)$ & \\
\hline \multicolumn{3}{|l|}{ Organ resection } & $1.000^{* *}$ \\
\hline Yes & $0(0 \%)$ & $9(100 \%)$ & \\
\hline No & $3(7.3 \%)$ & $38(92.7 \%)$ & \\
\hline \multicolumn{3}{|c|}{ Overall morbidity } & $1.000^{* *}$ \\
\hline Yes & $0(0 \%)$ & $7(100 \%)$ & \\
\hline No & $3(7 \%)$ & $40(93 \%)$ & \\
\hline $\begin{array}{l}\text { LOS (Median, } \\
\text { IQR) }\end{array}$ & None & $1(\mathrm{IQR}=1)$ & $0.232^{*}$ \\
\hline
\end{tabular}

\section{DISCUSSION}

In surgery clinics, inguinal hernia repair is one of the most common operations in adults. Based on location, inguinal hernias can be categorised as indirect, direct and femoral. ${ }^{10}$ Most patients present with a bulge or pain in the inguinal region. Patients may also have abdominal pain, nausea and vomiting at admission. Femoral hernias account for less than $5 \%$ of all inguinal hernias. ${ }^{1}$ These occur when there is weakness in the femoral canal, and they arise inferior to the inguinal ligament, protruding through the femoral ring. In the present study, the common symptoms were inguinal pain and abdominal pain.

\begin{tabular}{|l|l|l|l|}
\hline Variables & $\begin{array}{l}\text { Recurrence (+) } \\
(\mathbf{n}=\mathbf{3})\end{array}$ & $\begin{array}{l}\text { Recurrence (-) } \\
(\mathbf{n}=\mathbf{4 7})\end{array}$ & p-value \\
\hline $\begin{array}{l}\text { Age (Median, } \\
\text { IQR) }\end{array}$ & $67(\mathrm{IQR}=$ None) & $51(\mathrm{IQR}=35)$ & $0.984^{*}$ \\
\hline Gender & $0.542^{* *}$ \\
\hline Female & $3(9.1 \%)$ & $30(90.9 \%)$ & \\
\hline Male & $17(100 \%)$ & $0.414^{* *}$ \\
\hline Abdominal pain & $(0 \%)$ & \\
\hline Yes & $2(4.8 \%)$ & $40(95.2 \%)$ & \\
\hline No & $1(12.5 \%)$ & $7(87.5 \%)$ & $0.542^{* *}$ \\
\hline Nausea & $16(100 \%)$ & \\
\hline Yes & $0(0 \%)$ & $1.000^{* *}$ \\
\hline No & $31(91.2 \%)$ & \\
\hline Tachycardia & $1(8.8 \%)$ & $11(91.7 \%)$ & \\
\hline Yes & $2(5.3 \%)$ & $36(94.7 \%)$ & $0.414^{* *}$ \\
\hline No & $1(12.5 \%)$ & $7(87.5 \%)$ & \\
\hline Vomiting &
\end{tabular}

Femoral hernias are most commonly observed in patients between age 40 and 70 years and are quite rare in younger ages. ${ }^{11}$ In the Swedish Hernia Register, the patients' median age was $65 \pm 16.7$ years for those with femoral hernias ( $76 \pm 14.9$ years for emergency repairs and $59 \pm 15.5$ years for elective repairs). ${ }^{12}$ In the present study, the median age was 54.56 years, which was compatible with the age data in the literature.

The incidence of femoral hernias is higher in women and among right-sided hernias. ${ }^{13}$ According to the Denmark Hernia Registry, the incidence of femoral hernia repair in female patients is higher than in male patients $(72.7 \%$ vs. $27.3 \%)$. 
While femoral hernias are less prevalent, they are associated with an increased risk of incarceration and/or strangulation. In olderfemale patients, most femoral hernias present as incarcerated. Therefore, watching and waiting are not suitable for female patients. ${ }^{1}$ Previous studies have found that the incidence of femoral hernias requiring emergency surgery was significantly higher in women than in men. ${ }^{12,14}$ In accordance with the literature, the present study found that the rate of femoral hernias was higher in females (female/male ratio $=$ $33: 17)$ and those femoral hernias were more often seen on the right side ( $54 \%$ vs. $46 \%$ ).

From $35-40 \%$ of femoral hernias receive no diagnosis until signs develop of hernia strangulation or intestinal obstruction. These acute cases have a 10-fold increase in the risk of mortality. ${ }^{15}$ Such hernias can contain preperitoneal fat, omentum, peritoneum and bowel content. In the present study, most patients had incarcerated omentum inside the hernia sac. Other hernia sac contents included the small intestine and colon.

While physical examination has an important place in the diagnosis of inguinal hernia; the discrimination of femoral hernia is not easy with physical examination. Even more the diagnosis becomes more difficult with incarceration. Therefore, USG and CT are used to differentiate hernia types. ${ }^{16}$ USG is widely available, non-invasive and operator-dependent in differentiating inguinal from femoral hernias with $100 \%$ sensitivity and specificity. ${ }^{17}$ CT scan was found to be accurate in differentiating groin hernias in a retrospective study ${ }^{18}$ which also recommended CT as the first choice for investigating suspected small-bowel obstruction in the presence of a negative clinical examination in patients who had acute abdominal pain. In the present study, physical examination with USG were performed on all patients. CT was performed after USG to evaluate both intra-abdominal pathology and proximal/distal intestinal loop in 15 $(30 \%)$ patients with blood supply problems (reduction/absence) of the intestinal loop in the hernia sac.

General anesthesia is the preferred anesthesia type in emergency surgeries. ${ }^{19}$ In terms of postoperative morbidity, opinions differ on what types of anesthesia are effective for elective repairs or ineffective for emergency repairs. ${ }^{20}$ In the present study, postoperative complications occurred only in seven patients, who underwent general anaesthesia. Moreover, contrary to the literature, regional anesthesia was preferred.

According to the 2018 HerniaSurge group study, techniques that use mesh are preferred, and there is strong evidence to recommend them. In contrast, some surgeons believe that mesh use should be avoided as much as possible. ${ }^{5}$ Recently, due to the use of laparoscopy for hernia repair, the difference in results between open surgery using mesh and laparoscopic surgery has been minimised. However, in the HerniaSurge study, there was no consensus on the hernia repair technique used for emergency surgery. Unfortunately, there is no gold standard for femoral hernia emergency surgery. In Kunduz's study ( $n=27$ ), the Lichtenstein technique $(n=15)$ and the Rutkow plug technique ( $n=12$ ) were used for emergency hernia repair; no laparoscopic methods were used in emergency cases. $^{13}$ In Calik's study ${ }^{21}$, which included both emergency and elective cases, plug mesh repair (73.8\%) and the McVay herniorrhaphy (20\%) were the most commonly used operative procedures, and laparoscopy was used in only one case. In the present study, all cases were operated on using open surgery. Because none of the surgeries were laparoscopic, the authors could not compare that surgery type to open surgery. The McVay herniorrhaphy (66\%) was the technique used most frequently, but we also applied the Lichtenstein procedure and Rutkow mesh plug repair. It was determined that the technique used during the surgery and the use of prosthetic material depends on the surgeon performing the surgery. While traditional surgeons prefer surgery without the use of a prosthetic material, new surgeons prefer a prosthetic material during surgery. In addition, all of the postoperative recurrence cases ( 3 cases) were after McVay herniorrhaphy and in cases where a prosthetic material was not used. However, interestingly, both the type of surgery performed, and the use of prosthetic material were not associated with postoperative recurrence. There were no difference in morbidity, mortality, or recurrence among the three types of surgery we performed. A preference was observed for performing hernia repairs without mesh. In all cases, the traditional single oblique incision was used. In four cases, a midline laparotomy incision was added (three for bowel resection and one to repair a corona mortis injury).

Organ resection status is an important issue in femoral hernias. Due to anatomic complexity, the possibility of strangulation and necrosis in femoral hernias is higher. Suppiah et al., who examined 28 emergency femoral hernia surgeries, and Calik et al., ${ }^{21}$ who examined 43 , found rates of segmental intestinal resection anastomosis of $57.1 \%$ and $41.9 \%$, respectively. In Kunduz's study, the rate of intestinal resection anastomosis was $15 \% .{ }^{13}$ In the Swedish Hernia Register, which included 1,430 emergency surgeries, bowel resection was performed in $22.7 \%$, and female gender and femoral hernias were significant risk factors for postoperative intestinal obstruction. ${ }^{7}$ In a new study by Lui et al., the rate of organ resection was $39.4 \% .{ }^{22}$ In the present study, the rate of organ resection was $12 \%(n=6)$, of which five were small-bowel resections and one was an omental resection. The rate of organ resection was low compared to that in the literature. It was attributed to early surgical intervention in our patients. In the present study, organ resection during surgery increased the rates of both morbidity and mortality.

In Kunduz's study, ${ }^{13}$ the average hospital stay was $2.8 \pm 3.4$ days. In the studies by Suppiah et al. and Calik et al., , 5,21 the hospital stays averaged 3.04 and 8 days, respectively. In the present study, the mean duration of hospitalisation was $2.9 \pm$ 3.4 days, which was like the averages in other studies. Emergency surgery for incarcerated femoral hernias has been associated with a complication rate of up to $60 \%$ and a mortality rate of up to $10 \%{ }^{6,20}$ In the present study, complications developed in 
seven patients (14\%). The study's most common postoperative complication was seroma, which was seen in $6 \%$ of patients. The prevalence of seroma varied among other studies, being observed in $14.8 \%$ of cases in Kunduz's study. ${ }^{13}$ and $10.5 \%$ in Liu's study. ${ }^{4}$ It was believed that the seroma rate was low because of the high rate of spontaneous reduction and the low rate of organ resection. The other complications in the present study (ileus, haematoma, pneumonia, etc.) were seen only rarely, as they are in the literature. In the present study, the mortality rate was $4 \%$, which is low compared to the rates in the literature. The risk of mortality following an emergency procedure for a femoral hernia is 7 - to 10 -fold higher ${ }^{23}$ because patients undergoing emergency procedures belong predominantly to older age groups and generally have serious comorbidities. Femoral hernias more commonly present as incarcerated in patients who have significant comorbid diseases, and they are associated with both mortality and significantly higher rates of re-operation due to surgical complications. ${ }^{1}$ However, in the present study, advanced age had no effect on either morbidity or mortality. It must be noted that those patients whose comorbidities could not be evaluated due to lack of information were excluded from the study.

One review observed recurrences after femoral hernias at the rate of 2.2\% after laparoscopic surgery and 5.5\% after open surgery. In the Swedish Hernia Registry, femoral hernias were identified during recurrence surgeries in $41.6 \%$ of women; and only $4.6 \%$ of men. ${ }^{3}$ The recurrence rate for primary herniorrhaphies is $6.1 \%$; for recurrent herniorrhaphies, the recurrence rate is $22.2 \%$ on average and ranges from $11.8-75 \% .{ }^{24}$ In the present study, the overall rate of recurrence was $6 \%$ after primary femoral hernia repair and $0 \%$ after recurrent hernia repair.

Unfortunately, the present study has several limitations. First, it involved a single centre and included a small number of patients. Second, it was a retrospective study performed using electronic medical records, which might have introduced the potential for information bias. Moreover, the therapy option chosen was based on the preference of either the patient or the treating clinician, which might have introduced some effect of selection bias on the results. Therefore, a multicentre, prospective, randomised controlled study is necessary to identify the best method for treating incarcerated femoral hernias.

\section{CONCLUSION}

The present study found that preoperative tachycardia and organ resection also increased both morbidity and mortality. In addition, preoperative nausea and vomiting increased morbidity. Furthermore, morbidity was higher in patients in whom CT was used for diagnosis and in patients who were operated on under general anesthesia.

\section{ETHICALAPPROVAL:}

This study was started after receiving Ethics Committee approval from Clinical Research Ethics Committee of Van Yüzüncü Yıl University (Decision No. 2021/05-02; Date: 16/04/2021).

\section{PATIENTS' CONSENT:}

As the study was a retrospective one, patients' consent was waived.

\section{CONFLICT OF INTEREST:}

The authors declared no conflict of interest.

\section{AUTHORS' CONTRIBUTION:}

TK: Conception and study design, literature review, data collection, image analysis, statistical analysis, results, writing the manuscript and critical review of the manuscript.

UHI: Study design, data collection, image analysis, critical review of the manuscript.

MCK: Study design, image analysis, supervision.

\section{REFERENCES}

1. Halgas B, Viera J, Dilday J, Bader J, Holt D. Femoral hernias: analysis of preoperative risk factors and 30-Day outcomes of initial groin hernias using ACS-NSQIP. Am Surg 2018; 84(9):1455-61.

2. Memon AA, Siddiqui FG, Abro AH, Agha AH, Lubna S, Memon AS. Management of recurrent inguinal hernia at a tertiary care hospital of southern Sindh, Pakistan. World J Surg 2013; 37(3):510-5. doi: 10.1007/s00268-012-1897-1.

3. International guidelines for groin hernia management. Hernia 2018; 22:1-165. doi: 10.1007/s10029-017-1668-x.

4. Liu X, Zheng G, Ye B, Chen W, Xie H, Zhang T. Risk factors for surgical opportunity in patients with femoral hernia: $A$ retrospective cohort study. Medicine 2018; 97(34):e11826. doi: 10.1097/MD.0000000000011826.

5. Suppiah A, Gatt M, Barandiaran J, Heng M, Perry E. Outcomes of emergency and elective femoral hernia surgery in four district general hospitals: a 4-year study. Hernia 2007; 11(6):509-12. doi: 10.1007/s10029-007-0262-z.

6. Alimoglu O, Kaya B, Okan I, Dasiran F, Guzey D, Bas G, et al. Femoral hernia: A review of 83 cases. Hernia 2006; 10(1): 70-3. doi: 10.1007/s10029-005-0045-3.

7. Dahlstrand U, Wollert S, Nordin P, Sandblom G, Gunnarsson $U$. Emergency femoral hernia repair: A study based on a national register. Ann Surg 2009; 249(4):672-6. doi: 10.1097/SLA.0b013e31819ed943.

8. Alfieri S, Cina C, Savi G. Results and complications of femoral hernia repair. The Art of Hernia Surgery: Springer; 2018. p. 481-7.

9. Xie $Y$, Song $Y$, Ma D, Jian F, Zhang $S$, Lu A, et al. A prospective study on femoral hernia repair: is the inguinal better than the infrainguinal approach? J Surg Res 2019; 233:420-5. doi: 10.1016/j.jss.2018.08.034.

10. Malik AM, Khan A, Talpur KAH, Laghari AA. Factors influencing morbidity and mortality in elderly population undergoing inguinal hernia surgery. J Pak Med Assoc 2010; 60(45):45-7.

11. Sorelli PG, El-Masry NS, Garrett WV. Open femoral hernia repair: one skin incision for all. World J Emerg Surg 2009; 4(1):1-3. doi: 10.1186/1749-7922-4-44.

12. Andresen K, Bisgaard T, Kehlet H, Wara P, Rosenberg J. Reoperation rates for laparoscopic vs open repair of femoral hernias in Denmark: a nationwide analysis. JAMA

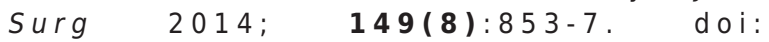




\subsection{1/jamasurg.2014.177.}

13. Kunduz E, Sormaz IC, Yapalak Y, Bektasoglu HK, Gok AF. Comparison of surgical techniques and results for emergency or elective femoral hernia repair. Ulus Travma Acil Cerrahi Derg 2019; 25(6):611-5. doi: 10.14744/tjtes. 2019.04524.

14. Ruhl CE, Everhart JE. Risk factors for inguinal hernia among adults in the US population. Am J Epidemiol 2007; 165(10):1154-61. doi: 10.1093/aje/kwm011.

15. Cox TC, Huntington CR, Blair LJ, Prasad T, Heniford BT, Augenstein VA. Quality of life and outcomes for femoral hernia repair: does laparoscopy have an advantage? Hernia 2017; 21(1):79-88. doi: 10.1007/s10029-016-1502-X.

16. Whalen HR, Kidd GA, O'Dwyer PJ. Femoral hernias. BMJ 2011; 343. doi: 10.1136/bmj.d7668.

17. Bradley M, Morgan D, Pentlow B, Roe A. The groin herniaan ultrasound diagnosis? Ann R Col Surg Eng 2003; 85(3):178. doi: 10.1308/003588403321661334.

18. Kitami M, Takase K, Tsuboi M, Rikimaru Y, Hakamatsuka T, Yamada $\mathrm{T}$, et al. Differentiation of femoral and inguinal hernias on the basis of anteroposterior relationship to the inguinal ligament on multidimensional computed tomography. J Comput Assist Tomogr 2009; 33(5):678-81. doi: 10.1097/RCT.0b013e3181977a0a.
19. Akıncı M, Yılmaz KB, Ergül Z, Şeker D, Külah B, Kulaçoğlu H. Emergent incarcerated groin hernias in adults: Presentations and clinical outcomes. Turkish J Surg 2011; 27(1):25-30. doi: 10.5097/1300-0705.UCD.703-11.01.

20. Kulah B, Duzgun AP, Moran M, Kulacoglu IH, Ozmen MM, Coskun MF. Emergency hernia repairs in elderly patients. Am J Surg 2001; 182(5):455-9. doi: 10.1016/s0002-9610 (01)00765-6.

21. Calik B, Karaman K, Atci R, Cetindag O, Ugurlu L, Aydin C, et al. Visceral organ resection during femoral hernia surgery is a predictor of morbidity. Int Surg 2015; 100(3):455-60. doi: 10.9738/INTSURG-D-14-00036.1.

22. Liu X, Ye L, Zheng G, Ye B, Chen W, Xie H, et al. A retrospective cohort study of open preperitoneal repair versus open suture repair for the treatment of emergency femoral hernia. Sci Rep 2020; 10(1):1-7. doi: 10.1038/ s41598-020-60722-y.

23. Dahlstrand U, Sandblom G, Wollert S, Gunnarsson U. Limited potential for prevention of emergency surgery for femoral hernia. World J Surg 2014; 38(8):1931-6. doi: 10.1007/s00268-014-2539-6.

24. Clyde DR, Beaux A, Tulloh B, O'Neill JR. Minimising recurrence after primary femoral hernia repair; is mesh mandatory? Hernia 2020; 24:137-42. doi: 10.1007/ s10029-019-02007-6. 